\title{
A COMPARATIVE EVALUATION OF PRESCRIBING PRACTICE OF ANTIBIOTIC PROPHYLAXIS IN HOSPIT ALS OF POKHARA VALLEY
}

\author{
Palikhe N*, Pokharel A*
}

\section{ABSTRACT}

The main objective of the study was to assess the prescribing practice of antibiotic prophylaxis for different surgeries in hospitals of Pokhara valley. A descriptive, quantitative, retrospective study was used to evaluate the patients who have undergone surgery between $15^{\text {th }}$ April $2002-14^{\text {th }}$ April 2003. A total of 950 patients were taken from the medical record for the study. Data about patient (age, sex), surgery (type and indication), antibiotic/s prophylaxis (dose, duration) and length of hospital stay were collected. Caesarean Section (CS) was the common surgery in Western Regional Hospital (WRH) followed by cholecystectomy, 31.1\% and 24.4\% respectively. In Manipal Teaching Hospital (MTH), dilatation and currettage (D and C, 21.6\%) was the most common surgery followed by hysterectomy (21\%). The mean length of stay in MTH for CS surgery was 7.97 days whereas 7.01 days for WRH. Significant difference was found in length of stay of two hospitals (p<0.05). Antibiotic prophylaxis was given preoperatively in MTH (87\%) and WRH (79.5\%) respectively. Antibiotic prophylaxis was given intraoperatively in $1.2 \%$ cases of MTH. In MTH, the total antibiotic duration in all surgeries is higher than WRH, significant difference was found only in cholecystectomy (p<0.05). In both hospitals Ampicillin+Cloxacillin was the most commonly used regimen, $12.4 \%$ in WRH and $34 \%$ in MTH. In WRH, Ciprofloxacin/Cefotaxim was also used by $12.4 \%$. More than $79.1 \%$ of the patients were exposed to, at least, two antibiotics as a prophylaxis in WRH where as more than 63.0\% in MTH. Penicillin was found to be mostly used in both hospitals.

\section{Key Words: Antibiotic prophylaxis, Surgery.}

\section{INTRODUCTION}

Clinical surgery has witnessed a remarkable reduction in postoperative wound infection during the past 25 years. ${ }^{1}$ This reduction has been attributed to improvements in aseptic surgical techniques and use of antibiotic prophylaxis. First generation cephalosporins are considered the most appropriate drugs for the majority of the procedures. ${ }^{2-4}$

The recommended beginning time for administration is just before the anesthesia induction, with the exceptions being caesarean section. In the majority of the procedures, a single dose is considered adequate. ${ }^{5}$ In spite of extensive knowledge about the effectiveness of antibiotic prophylaxis; administrative regimens are often inappropriate in practice. ${ }^{6-9}$

The practice of use of prophylactic antibiotic in different surgeries is now becoming essential because of increased chance of hospital-acquired infection and also for prevention of postoperative infectious morbidity. The regimen for prophylactic antibiotic is different in hospitals. Broader spectrum of antibiotics and higher generation of cephalosporins and combination of two antibiotics are found to be prescribed in hospitals in surgeries for prophylaxis.

* Kathmandu Medical College, Sinamangal, Kathmandu, Nepal.

** KUMS, Kathmandu, Nepal.

Address for correspondence : Dr. Nami Palikhe

Kathmandu Medical College, Sinamangal, Kathmandu, Nepal.

Email: pnamu22@gmail.com 
The inappropriate use of antimicrobial agents has resulted not only in unnecessary expense or overuses of antimicrobial agents but also in the development of drug-resistant bacteria. Ideally, an appropriate spectrum of prophylactic antimicrobial agents for surgery should be saturated in the body fluids and at the surgical site during the operation but they should be terminated as soon as possible to avoid the occurrence of resistant organisms. So, this study aims to determine the practice of prophylactic antibiotic in different surgeries in one region of Nepal.

Nowadays there is a social change toward quality in all-human activities, including medical activity. It is important that health professionals participate in studies and implementation of quality programs, including assessments of personal practice patterns. Certainly, the use of antibiotic as a prophylactic deserves to be periodically evaluated. In this procedure, the observation of the guideline would result in cost reduction, and moreover, lower adverse reaction risks, infection morbidity reduction, length of stay reduction, and microbial resistance reduction would be expected.

\section{MATERIALS AND METHODS}

The prescribing pattern of antibiotic prophylaxis was investigated in different surgeries of major hospitals in Pokhara valley. The two hospitals were Western Regional Hospital (WRH) and Manipal Teaching Hospital (MTH). A descriptive, quantitative, retrospective study was used to evaluate the patients who has undergone surgery in the year between $15^{\text {th }}$
April $2002-14^{\text {th }}$ April 2003. Medical records of in- patients of age falls between 18 - 65 years having no surgical history in past 1 month and absence of infection prior to surgery were reviewed retrospectively. Hospital numbers of all the patients' who had undergone surgery in the 2059 BS were noted from the record book of medical record section. Then systematic random sampling method was used for the selection of the patient for the required sample size. Data about type of surgeries of hospitals, length of hospital stay, timing of prophylaxis, duration of therapy, commonly used regimens were collected. Comparisons of the same variables were done between two hospitals by student's 't' test, where appropriate. Continuous outcome measures were analysed using the independent ' $t$ ' test for dependent variables. Ninety-five percent (95\%) confidence intervals (CI) were also reported when appropriate. $\mathrm{P}<0.05$ was considered statistically significant.

\section{RESULTS}

\section{Types of surgeries in hospitals}

Caesarean section (CS) (31.1\%) was the common surgery in WRH followed by cholecystectomy (24.4\%). In MTH, dilatation and curettage (D and C) was the most common surgery followed by hysterectomy. Only $3.2 \%$ prostectomy was found in WRH. In both hospitals cholecystectomy was mostly found in female than male. In WRH $16.4 \%$ and in MTH 4\% of female had a cholecystectomy. Similarly herniorraphy was found in $6.7 \%$ and $6.8 \%$ of male in WRH and MTH respectively.

Table I : Common Surgeries in WRH and MTH according to sex

\begin{tabular}{l|cc|c|cc|c}
\hline \multirow{2}{*}{ Type of Surgery } & \multicolumn{3}{|c|}{ WRH, n (\%) } & \multicolumn{3}{c}{ MTH, n (\%) } \\
\cline { 2 - 7 } & Male & Female & Total & Male & Female & Total \\
\hline CS & 0 & $140(31.1)$ & $140(31.1)$ & 0 & $69(13.8)$ & $69(13.8)$ \\
\hline Cholecystectomy & $36(8.0)$ & $74(16.4)$ & $110(24.4)$ & $16(3.2)$ & $20(4.0)$ & $36(7.2)$ \\
\hline Hysterectomy & 0 & $68(15.1)$ & $68(15.1)$ & 0 & $105(21.0)$ & $105(21.0)$ \\
\hline D and C & 0 & $40(8.9)$ & $40(8.9)$ & 0 & $108(21.6)$ & $108(21.6)$ \\
\hline Herniorraphy & $30(6.7)$ & $2(0.4)$ & $32(7.1)$ & $34(6.8)$ & $3(0.6)$ & $37(7.4)$ \\
\hline Prostectomy & $20(4.5)$ & 0 & $20(4.4)$ & $16(3.2)$ & 0 & $16(3.2)$ \\
\hline Others & $10(2.2)$ & $30(6.7)$ & $40(8.9)$ & $79(15.8)$ & $50(10)$ & $129(25.8)$ \\
\hline \multicolumn{1}{c}{ Total } & $\mathbf{9 6 ( 2 1 . 4 )}$ & $\mathbf{3 5 4 ( 7 8 . 6 )}$ & $\mathbf{4 5 0 ( 1 0 0 )}$ & $\mathbf{1 4 5 ( 2 9 . 0 )}$ & $\mathbf{3 5 5 ( 7 1 . 0 )}$ & $\mathbf{5 0 0 ( 1 0 0 )}$ \\
\hline \multicolumn{4}{r}{}
\end{tabular}

Table II : Length of Stay according to type of surgery

\begin{tabular}{lc|c|c|cc}
\hline \multirow{2}{*}{ Type of Surgery } & \multicolumn{4}{c}{ Length of Stay (in days) } & \multirow{2}{*}{ P- value } \\
\cline { 2 - 5 } & \multicolumn{2}{c}{ WRH (N=450) } & \multicolumn{2}{c}{ MTH (N=500) } & S.D \\
\cline { 2 - 5 } & Mean & S.D & Mean & 2.3 & 0.035 \\
\hline CS & 7.0 & 2.3 & 8.0 & 2.5 & 0.515 \\
\hline Cholecystectomy & 4.1 & 2.6 & 4.5 & 4.2 & 0.000 \\
\hline Hysterectomy & 6.4 & 2.0 & 9.5 & 1.6 & 0.041 \\
\hline D and C & 3.4 & 3.1 & 2.3 & 1.7 & 0.001 \\
\hline Herniorraphy & 2.3 & 1.1 & 4.0 & 2.7 & 0.066 \\
\hline Prostectomy & 4.7 & 1.8 & 6.7 & 3.6 & 0.205 \\
\hline Others & 5.7 & 4.7 & 4.6 & & 0.6 \\
\hline
\end{tabular}




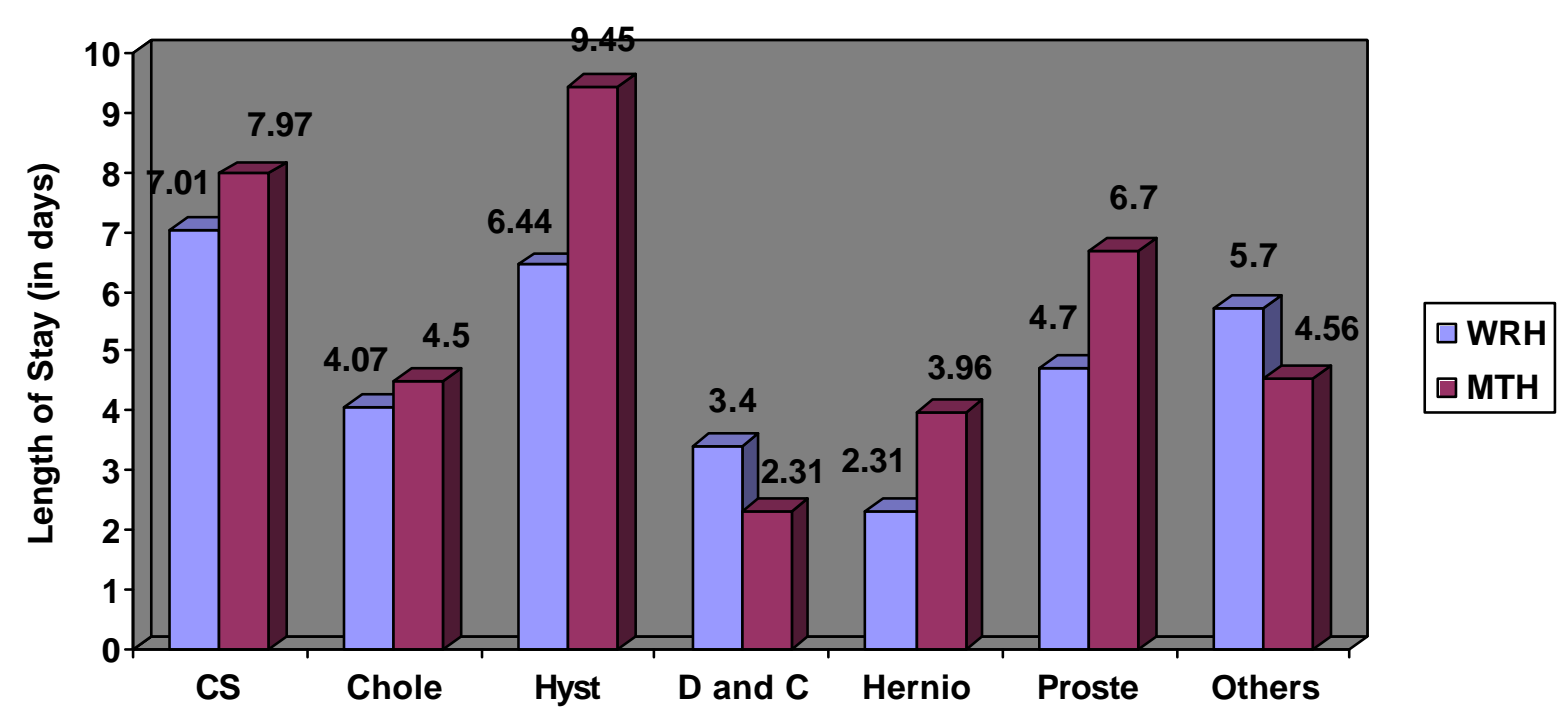

Fig. 1 : Comparison of length of Stay of different surgeries in two hospitals.

Table III : Time of Antibiotic Prophylaxis

\begin{tabular}{l|c|c}
\hline \multirow{2}{*}{ Timing } & WRH (N=258) & MTH (N=500) \\
\cline { 2 - 3 } & $\mathbf{n}(\mathbf{\%})$ & $\mathbf{n}(\mathbf{\%})$ \\
\hline Preoperatively & $205(79.5)$ & $435(87.0)$ \\
\hline Intraoperatively & 0 & $6(1.2)$ \\
Postoperatively & $53(20.5)$ & $59(11.8)$
\end{tabular}

Table IV : Total antibiotic duration in different surgery

\begin{tabular}{l|c|cc|c|c|cc}
\hline \multirow{2}{*}{ Type of surgery } & \multicolumn{4}{|c|}{ WRH (N=450) } & \multicolumn{3}{c}{ MTH (N=500) } \\
\cline { 2 - 8 } & $\begin{array}{c}\text { Total duration } \\
\text { of Ab }\end{array}$ & SD & $\mathbf{n}$ & $\begin{array}{c}\text { Total duration } \\
\text { of Ab }\end{array}$ & SD & $\mathbf{n}$ & P- value \\
\hline CS & 6.2 & 1.81 & 140 & 6.3 & 1.92 & 69 & 0.625 \\
\hline Cholecystectomy & 2.7 & 1.51 & 110 & 4.5 & 2.65 & 36 & 0.000 \\
\hline Hysterectomy & 6.1 & 1.75 & 68 & 6.4 & 1.98 & 105 & 0.440 \\
\hline D and C & 2.9 & 1.1 & 40 & 2.6 & 1.5 & 108 & 0.437 \\
\hline Herniorraphy & 2.7 & 1.31 & 32 & 3.0 & 1.83 & 37 & 0.590 \\
\hline Prostectomy & 4.8 & 1.97 & 20 & 5.3 & 1.34 & 16 & 0.558 \\
\hline Others & 4.7 & 2.28 & 40 & 4.3 & 2.42 & 129 & 0.545 \\
\hline
\end{tabular}

\section{Length of Hospital Stay}

The mean length of stay in MTH for CS surgery was 7.97 days whereas 7.01 days for WRH. Significant difference was found in length of stay of two hospitals $(\mathrm{P}<0.05)$. Similarly there was a significant difference in the mean length of stay (in days) for hysterectomy in WRH and MTH (6.4 vs. 9.5; $\mathrm{P}<0.05$ ). Except $\mathrm{D}$ and $\mathrm{C}$, in all the cases of MTH have longer hospital stay.

\section{Timing of prophylaxis}

In WRH, the first dose administration time of prophylactic antibiotic was not mentioned in $192(42.6 \%)$ cases. So, only those cases were taken for the analysis where information of administration time was available.

Antibiotic prophylaxis was given preoperatively in MTH (87\%) and WRH (79.5\%). Antibiotic prophylaxis was given intraoperatively in $1.2 \%$ cases of MTH.

\section{Duration of therapy}

In MTH the total antibiotic duration in all surgeries were higher than WRH, but significant difference was found only in cholecystectomy $(\mathrm{P}<0.05)$. Almost in all the cases, the duration of total antibiotic/s were found higher.

In both hospitals Ampi+Cloxa was the most commonly used regimen, $12.4 \%$ in WRH and 34\% in MTH. In WRH Cipro/ Cefotaxim was also used by $12.4 \%$. Ciprofloxacin/Gentamycin (Cipro/Genta) (12\%) combination was the third commonly used regimen in WRH where as Cipro $(28.4 \%)$ and Ampi+Cloxa/Genta (22.4\%) in MTH. The variation in the use of antibiotic regimen was found in WRH compared to MTH. Most of the guidelines preferred first generation of cephalosporin (cefazolin) for the antibiotic prophylactic but 
Table V : Commonly used regimen in two hospitals

\begin{tabular}{l|c|l|c}
\hline \multicolumn{1}{c|}{ Regimen WRH } & n (\%) & \multicolumn{1}{c}{ Regimen MTH } & n (\%) \\
\hline Ampi + Cloxa & $56(12.4)$ & Ampi + Cloxa & $170(34.0)$ \\
\hline Cipro / Cefotaxim & $56(12.4)$ & Cipro & $142(28.4)$ \\
\hline Cipro / Genta & $54(12.0)$ & Ampi + Cloxa / Genta & $112(22.4)$ \\
\hline Ampi + Genta & $50(11.1)$ & & \\
\hline Cipro & $44(9.8)$ & & \\
\hline
\end{tabular}

Table VI : Number of antibiotic/s used for prophylaxis

\begin{tabular}{c|c|c}
\hline \multirow{2}{*}{ No of Antibiotic/s } & WRH (N=450) & MTH (N=500) \\
\cline { 2 - 3 } & $\mathbf{n}(\boldsymbol{\%})$ & $\mathbf{n}(\boldsymbol{\%})$ \\
\hline 1 & $94(20.9)$ & $185(37.0)$ \\
\hline 2 & $290(64.5)$ & $203(40.6)$ \\
\hline 3 & $54(12.0)$ & $112(22.4)$ \\
\hline$>3$ & $12(2.6)$ & \\
\hline
\end{tabular}

in our study penicillin was found to be mostly used in both hospital.

\section{Number of antibiotic/s used}

More than $79.1 \%$ of the patients were exposed to, at least, two antibiotics as a prophylaxis in WRH where as more than $63.0 \%$ in MTH. Only one antibiotic was given in $20.9 \%$ of cases, two antibiotics in $64.5 \%$, three antibiotics in $54 \%$ and greater than three antibiotics in $12 \%$ of cases of WRH. Similarly only one antibiotic was given in $37 \%$ of cases two antibiotics in $40.6 \%$ and three antibiotics in $22.4 \%$ of cases of MTH.

\section{DISCUSSION}

The reason for CS surgery was the most common in WRH might be due to high patient inflow in WRH. This is the oldest and regional hospital of Pokhara valley so; most of the delivery cases generally come to the WRH than MTH.

The goals in prophylaxis are to achieve inhibitory antimicrobial levels at incision and to maintain adequate levels for the duration of the procedure. Studies of animals have demonstrated that antimicrobial drugs are most effective for preventing postoperative infection when they are administered before the operation begins. In nearly all-recent clinical trials, the administration of prophylactic agents has been initiated within 120 minutes before incision. Recent reports have confirmed the importance of this timing. ${ }^{10,11,12}$ Indeed, pharmacokinetic data indicate the desirability of administration as close to the time of incision as is practical e.g. at anesthesia induction. ${ }^{13,14}$ If a drug with a short half-life is given 120 minutes before incision its levels may be very low during most of the procedure. Postoperative initiation of antimicrobial "prophylaxis" is still relatively common in practice ${ }^{15,16,17}$ but is not recommended, nor is the administration of the first dose after incision desirable except for the case of CS. During CS prophylaxis should be delayed until cord is clamped in order to prevent the drug reaching to neonate.

In WRH and MTH, in most of the cases preoperative administration of antibiotic prophylaxis was found. Though the postoperative administration of antibiotic prophylaxis was not effective, it was found in our study. In case of CS, where the administration time should be after the clamping of cord; prophylaxis was given preoperatively in $92.7 \%$ and $55.7 \%$ in MTH and WRH respectively. In the rest of the cases postoperative doses of antibiotic were given. Those postoperative doses were neither administered after clamping of cord nor immediately after the completion of operation. These doses were given only after the patient was brought to the post-operative ward.

The main problems in the antibiotic prophylaxis were the time and duration. Patients who did not receive the antibiotic at the optimal time received less protection, as described in the literature.

The duration of prophylaxis was longer than recommended in most of the cases. The long duration of prophylaxis regimen exposed the patients to adverse drug reactions (in case of cephalosporins use: thrombophlebitis, gastrointestinal symptoms, allergic reactions, drug fever, coagulopathy, eosinophilia, and other more rare reactions) and certainly increases the possibility of microbial resistance, not only in these patients, but also in the hospitals. ${ }^{18}$

Postoperative doses of antibiotic for prophylaxis should not be given for any operation. ${ }^{19}$ In procedures lasting 3 hours or less, a single prophylactic dose is usually sufficient. Procedures are lasting greater than three hours require an additional effective dose. ${ }^{20}$ 
The results obtained from the study revealed that there was a practice variation in the use of an antibiotic prophylaxis in both hospitals. Most commonly used antibiotic for prophylaxis was Ampi+Cloxa i.e. Penicillin group of antibiotics. In most of the cases, the administration time was preoperatively. The duration of prophylaxis was unnecessary longer, in most of the cases same as that of the therapeutic duration in both hospitals. The longer duration of prophylaxis were shown to have no additive effect as compared with single dose of prophylaxis.

The hospitals infrequently met the international published guidelines for antibiotic prophylaxis and compliance varied by type of procedure and also within the procedure.

\section{ACKNOWLEDGMENT}

We would like to express our acknowledgment to Nepal Health Research Council (NHRC), Ramshahpath, Kathmandu for selecting this study for western regional grant.

\section{REFERENCES}

1. Holzheimer RG, Haupt W, Thiede A, Schwarzkopf A. The challenge of postoperative infections: does the surgeon make a difference? Infect Control Hosp Epidemiol 1997; 18:449-56.

2. Page CP, Bohnen JMA, Fletcher JR, McManus AT, Solomkin JS, Wittmann DH. Antimicrobial prophylaxis for surgical wounds. Guidelines for clinical care. Arch Surg 1993;128:7988.

3. Waddell TK, Rotstein CD. Antimicrobial prophylaxis in surgery. Can Med Assoc J 1994; 151: 925-31.

4. Martin C, Andreassian B, Baron D, et al. Antibioprophylaxie en Milieu Chirurgical Chez L' adulte. Annales de Chirurgie 1993; 47:484-91.

5. DiPiro JT, Cheung RPF, Bowden TA Jr, et al. Single dose systemic antibiotic prophylaxis in surgical wound infections. Am J Surg 1986; 152:552-9.

6. Bonal J, Castro I, Farre R, Saura R, Perez JM. Programme d' amálioration de la qualité de la prophylaxie chinurgicale antibiotique. Le Pharmacien Hospitalier 1996; 31 (124) :25-7.

7. Delgadillo J, Ramirez R, Cebrecos J, Arnau JM, Laporte JR.
Utilización de antibióticos en prophylaxis quirúrgica. Características y consecuencias. Medicina Clinica 1992; 100:404-6.

8. Thomas M, Govil S, Moses BV, Joseph A. Monitoring of antibiotic use in a primary and a tertiary care hospital. JClin Epidemiol 1996; 49: 251-4.

9. Avery $\mathrm{CME}$, Jamienson $\mathrm{N}$, Calne RY. Effective administration of heparin and antibiotic prophylaxis. Br J Surg1995; 82: 1136-7.

10. Bencini PL. Galimherti M. Signorini M. Crosti C. Antibiotic prophylaxis of wound infections in skin surgery. Arch Dematol$1991 ; 127: 1357-60$

11. Dellinger EP. Antibiotic prophylaxis of wound infections in skin sur gery: is four days too much? [editorial] Arch Dermatol 1991: 127:1394-5.

12. Classen DC. Evans RS. Pestotnik SL. Horn SD. Menlove RL, Burke JP. The timing of prophylactic administration of antibiotics and the risk of surgical-wound infection. NEngl $J$ Med 1992; 326:281-6.

13. DiPiro JT. Vallner JJ. Bowden TA Jr. Clark BA. Sisley JF. Intraoperative serum and tissue activity of cefazolin and cefoxitin. Arch Surg 1985: 120:829-32.

14. Galandiuk S. Polk HC Jr. Jagelman DG. Fazio WW. Re-emphasis of priorities in surgical antibiotic prophylaxis. Surg Gynecol Obstet $1989 ; 169: 219-22$.

15. Classen DC. Evans RS. Pestotnik SL. Horn SD. Menlove RL, Burke JP. The timing of prophylactic administration of antibiotics and the risk of surgical-wound infection. NEngl $J$ Med 1992; 326:281-6.

16. Crossley K. Gardner LC, Task Force on Prophylactic Antibiotics in Surgery. Antimicrobial prophylaxis in surgical patients. JAMA 1981; 245: 722-6.

17. Shapiro M. Townsend TR. Rosner B. Kass EH. Use of antimicrobial drugs in general hospitals: pattems of prophylaxis. N Engl J Med 1979; 301:351-5

18. Heineck I, Maria BC, Eloir PS. Prescribing practice for antibiotic prophylaxis for 3 cormonly performed surgeries in a teaching hospital in Brazil. AJIC Am J Infect Control 1999;27:296-300.

19. Scottish Intercollegiate Guidelines Network. Antibiotic Prophylaxis in Surgery. A National Clinical Guideline. Sign Publication 2000; Number 45.

20. MCW and FMLH Antibiotic Guide; Froedtert Hospital.

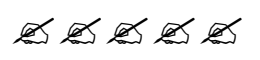

